\title{
The Exploration of Skilled and Less-Skilled EFL Graduate Students' on L1 and L2 Writing Strategies
}

\section{Syaadiah Arifin ${ }^{1 *}$}

Muhammadiyah University of Prof. Dr. Hamka, Jakarta, Indonesia

e-mail: syaadiah.arifin@uhamka.ac.id

\begin{abstract}
This study aims to analyze the similarities, differences, and transferability of students' writing strategies in L1 (Indonesian) and L2 (English). Data were obtained from four participants majoring in English Education, two males and two females, which were categorized into skilled and less-skilled writers. The data were collected for four months using various methods, namely think-aloud protocols (TAPs), retrospective and semi-structured interviews, observations, and written drafts. The result showed that students employed similar personal strategies while writing in Indonesian (L1) and English (L2). This means that they transferred $L 1$ strategies to $L 2$ with some variances and similarities. The skilled writers viewed writing as a cyclical process of planning, writing, reading/rereading, rehearsing, and revising their texts. Meanwhile, less-skilled writers tended to employ linear and less recursive strategies. Furthermore, subsequent studies need to be conducted using these research findings and suggestions.
\end{abstract}

Keywords: Writing Strategies, Similarities, Differences, Transferability

\section{Introduction}

Writing is viewed as an ambiguous language activity which requires different skills and procedures (Harmey, 2020; Wong \& Russak, 2020). This task is more challenging in L2 than L1 because it requires certain competencies such as spelling, vocabulary, usage, and sentence structure (Alfaki, 2015; Eliwarti \& Maarof, 2014; Wei et al., 2020). However, other intricacies also tend to stem from some shreds of evidence, which were confronted with cultural discrepancies, selecting appropriate writing strategies, familiarizing with the genres, as well as academic proficiency in target languages (Al-Gharabally, 2015; Ortega, 2015). Nonetheless, writing strategies play a substantial role in this process. Conversely, when properly utilized, it affects the students' quality of writing and makes it easier to distinguish between skilled and less-skilled writers (Chien, 2012; Khongput, 2020).

Furthermore, there is little or no improvement in the writing skills of L2. The difficulties encountered by Indonesian students (L2), has already been addressed by certain studies. These problems emerge as a result of the product-based approach implemented in schools rather than the process-based procedure, and the method of teaching applied.

Several English teachers or lecturers only focus on the final result rather than guide the students through the process of text generation using systematic procedures. All they do is assign topics to students requesting them to write several paragraphs while they make corrections on some of the grammatical errors and they overlook the significant phase of the writing process (Miftah, 2015). Writing is not merely about vocabulary, structures, sentences, and paragraphs, however, it requires a series of processes in which students need to develop and explore their thoughts, and ideas, by reading books and articles, as well as having discussions with their friends and teachers (Lan et al., 2019; Mostafa \& Crossley, 2020). In addition, the actual process certainly requires an input of many efforts and time by both learners and teachers.

${ }^{*}$ Corresponding author.

Received 24 June 2020; Accepted 28 August 2020; Available online 01 September 2020

(C) 2020 JPI. All Rights Reserved 
The students also have to undergo some stages, such as pre-writing, planning, drafting, and reviewing, which consist of revising and editing (Milicevic et al., 2020; Sumarwati, 2019). Therefore, it is a cyclical and reflective process, and students are usually faced with some problems. However, these difficulties are overcome by applying certain strategies used by skilled workers during each stage.

Skilled writers were aware that writing was not linear and infrequently wrote repetitive sentences. However, the less-skilled writers did not experience writing as repeated processes due to their inability to produce ideas and revise the writings to develop their envisioned meanings. Planning and revising strategies were applied more effectively by skilled-writers compared to less-skilled writers. This tends to be of great benefit to the teachers because the application of these strategies aids them in training less-skilled writers. Unfortunately, students are rarely exposed to this process because they usually ignore their significance. Consequently, only a few studies concerning this procedure has been carried out in Indonesia (Ardila, 2020; Junianti et al., 2020; Mistar \& Parlindungan, 2014). However, most of those studies concentrated on the strategies used by the students in L2. In addition, inadequate comparative analysis has been carried out between skilled (L1) and less-skilled (L2) writers in EFL contexts. Research conducted by (Wei et al., 2020) stated that 1) L2 writers' perception of L2 writing difficulty and L2 writing proficiency were found as individual factors relevant to L1-to-L2 rhetorical transfer; 2) L2 writers' perception of L2 writing difficulty was positively asso- ciated with the transfer related to the argument organization respecting within-paragraph organization and consideration of a thesis; 3) L2 writers' L2 writing proficiency had a negative association with the transfer that did not reflect the active role of $L 1$ rhetoric. The other research conducted by (Lan et al., 2019) stated that grammatical complexity is regarded as a crucial feature of L2 writing, the construct has been widely utilized in empirical research to gauge L2 writing quality and development, particularly in English. Therefore, this research aims to describe the similarities and differences in the writing strategies applied by both skilled and less-skilled students, including the effect of transferability.

\section{Method}

The research sample comprises four graduate students purposively selected from the English Education Department in the first semester of 2019/2020 academic year. Therefore, to determine skilled and less-skilled subjects, participants were required to write argumentative essays on some specific English and Indonesian themes within 70 minutes in each language and on different days. Two professional raters were assigned to rank the students' writing. Their marks were used as primary indicators to categorize students into skilled and less skilled writers. Less skilled writers demonstrated difficulties in writing English profoundly, while skilled writers were able to deliver meaningful ideas to readers. Moreover, all writers unveiled good knowledge of grammar, with the application of proper and wide-ranging vocabulary. This ability was due to their educational background, although the real contents of less-skilled writers remained elusive and superficial.

All participants used in this research were relatively-skilled Indonesian writers that have studied the language for a long time. However, this research focused on students'L2 writing to determine skilled and less-skilled writers. In addition, students were asked to write in L1 to determine whether their writing strategies in L1 affected their L2 writing.

Secondly, data were obtained from the lecturers teaching Academic Writing Course on students' performance in L2 writing. Four students were classified as L2 skilled writers; however, only two were eligible to join the research due to their ability to verbalize and write their thoughts simultaneously, also known as the think-aloud procedure. Furthermore, two less skilled writers were chosen based on their training on TAPs as the first indicator and their inability to write and verbalize simultaneously. 
The qualitative data were gathered from multiple data analysis methods, namely thinkaloud protocols (TAPs), direct observations, and interviews. These four participants were asked to write two texts in Indonesian and English titled "Homeschooling is better than the publicschool educational system", and "Pengaruh Televisi terhadap Perkembangan Anak," Under think-aloud conditions. TPAs were employed to allow the collection of data on students' cognitive processes in writing, which enabled them to verbalize their thoughts and feeling while writing. Therefore, this enabled the implicit procedure and mental activities of specific tasks and helped capture studen' cognitive activities, processes and strategies (Bowles, 2010; Latif, 2009).

In addition, to TPAs, students' writing was also collected for data analysis, while monitoring and observing their TAPs. The observation technique was also employed to understand students' writing difficulty, repeated words, paused, revised, rehearsed, read, and reread. Therefore, to carry out this process, a small recorder was placed on the participants' desk, with a video recorder set behind them. This was followed by a retrospective interview which allowed each writer to explain their reasons for choosing certain writing strategies such as, pausing, reading and rereading the texts. Thematic analysis was performed to analyze the collected data from the interviews.

A week later, a semi-structured interview, was held to determine the students' educational background, reading habits, writing skills in Indonesian and English and, previous instructions and experience in writing. The data collected were analyzed using Wongs' coding taxonomies, which differentiates between revising and editing (Wong, 2005).

\section{Result and Discussion}

\section{The Similarities and Differences of Skilled and Less-Skilled Students' writing strategies in L1 and L2 Planning Stage}

Data analysis from TPAs indicated that skilled writers adopted similar strategies when they wrote in L1 and L2. Immediately the topic was issued to them, they read and reread the prompt (Rt) before evaluating the related problem. After identifying the problem, they devoted some time to plan their essay using the planned globally $(\mathrm{Plg})$ method, with their paragraph organized in accordance with the content (Op). Furthermore, the students wrote detailed outlines and mentioned their stance for agreeing or disagreeing with the topic (Tp) in the planning stage. To generate more ideas, the students read and reread their written (Rd) sentences, while pausing $(P)$ at intervals. Based on the data gathered from retrospective interview, both of students paused $(P)$ due to several reasons, such as difficulty in understanding the idea to be stated, reformulating ideas, and while planning on next line of action. In this research, pausing is classified as one of the cognitive strategies.

However, the L1 and L2 planning patterns adopted by less-skilled writers differed from skilled writers as they read and reread (Rd) the topic several times for proper comprehension. For instance, it was observed that the student carried out mental planning when writing in L1 and L2, while the other student spent a little time when planning her texts in both writing strategies. Consequently, they were often changed their already written sentences or paragraphs due to inappropriate planning. Therefore, less-skilled writers often used local planning (PII) because they did not have any outlined strategy or guidance to assist them with the writing process. The following are some excerpts from the interview section with the participants:

Dinna: "I always plan before the actual writing and list down my ideas in detail. Furthermore, during writing, I read and reread the topic several times. I also try to revise and edit all that I've written, while making corrections when necessary." 
Ren: "when I write in English or Indonesian, I always read the topic several times before arranging some ideas in my mind. I always think of what to write before commencing with the actual writing."

Rita: "I outline the main points of what I am going to write to make the process easy for me. Also, I have been writing short stories in Indonesian since high school. This has encouraged me to write fluently in Indonesian fluently and has built my confidence level. Therefore, without much effort, whenever a topic is assigned to me in Indonesian, ideas are generated with planning. However, in English, the reverse is the case as I tend to have a problem developing my ideas."

\section{Writing/ Drafting Stage}

In this stage, Aldy and Dinna consistently stuck to their plans, while writing in L1 and L2. Dinna frequently relied on reading/rereading $(R d)$ the essay, while rehearsing $(R h)$ to generate ideas. Furthermore, Dinna paused $(P)$ at intervals when writing in $L 1$ and $L 2$ but not as often as Aldy. Dinna also revised $(R v)$ and edited the text (Ed) occasionally. When writing in L2, Dinna used more reading/rereading ( $R d)$ strategies to generate ideas than when writing in L1. Moreover, Dinna revised the text to determine omitted phrases (Rvo), spelling error (Esp), and grammatical errors ( $\mathrm{Eg}$ ) with the addition of clauses (Rva), when necessary. Conversely, Aldy relied on reading/ rereading $(R d)$ and rehearsing $(R h)$ to generate ideas when writing in $L 1$ and L2. Aldy also revised (Rv) the text several times to determine omitted sentences (Rvo). Aldy also paused $(P)$ a lot when writing in $L 1$ and $L 2$.

However, Ritas rarely read/ reread (Rd), stopped to revise and edit, or rehearsed (Rh) the text. While Ren used more writing strategies than Rita while depending on reading/rereading $(\mathrm{Rd})$ and rehearsing $(\mathrm{Rh})$ to generate ideas. In addition, both of them used their strategies in low frequency and rarely revised or edited their texts in this stage. Difficulties in writing should not be over- looked as learning to write is always time and energy consuming and demands both teachers' and learners' devotion no matter what resources are used (Lei, 2016).

\section{Reviewing Stage}

Aldy and Dinna stated that they evaluated (Ev) the texts in L1 and L2 by reading and scanning several times to examine what they assumed was right at the writing stage. They reviewed $(R v)$ their texts to discover the proper flow of essays in order to obtain more connected ideas. Furthermore, they went over their essay structure, read the text judiciously, and applied external revisions/editing.

However, in this reviewing stage, they only did a few internal revisions/editing. During the retrospective interview, they stated that they evaluated (Ev) their text comprehensively to monitor their writing in the writing/drafting stage. Therefore, they only carried out a few internal revisions and editing in this stage. However, Ren and Rita evaluated (Ev) their texts once by reading and scanning. In addition, after completing their essay, they looked through their text and made minor corrections by concentrating only on editing basic grammar mistakes, and spellings.

The first significant discovery concerning the students writing processes is that they exhibited similar writing style when writing in both languages (Indonesian and English) with some minor variations. For example, Aldy, Dinna, Rita adopted the same stages: planning, writing/drafting, and reviewing. Ren verbally planned what to write, while writing in L1 and L2, while Rita wrote out the main points. Therefore, meta-cognitive strategies were used by all writers with various degrees when planning their essays. Meta-cognitive knowledge impacted greatly to the quality of writing. There existed a difference in the metacognitive awareness of L1to-L2 rhetorical transfer between lower- and higher- proficiency L2 writers (Wei, 2020). According to several studies, writers that spend sufficient time in planning, and appropriately organizing paragraphs as well as contents, were successful. In contrast, those with little 
planning experienced difficulty in processing their writing task. Globally, skilled writers spend time planning to enable them to keep track of their main ideas (Victori, 1999; Wei, 2020; Wei et al., 2020). Sufficient planning can greatly affect the quality of one's writing (Mahmoudi, 2017).

The second significant discovery is the use of akin patterns by skilled writers when writing/ drafting in $L 1$ and $L 2$. They used to read and rereading in high frequency, which enabled them to be aware of the recursive way of writing. Furthermore, they also revised and edited their essays while reading/ rereading. According to them, young learners and less-skilled novel writers usually instigate their writing with insufficient plans using easy techniques. This strategy is called "natural" or "unproblematic" since it embraces any planning or revision. Rita wrote the various ideas that came into her mind while writing in L1 and L2. Moreover, Rita applied a linear writing style while rehearsing and repeating the words to generate ideas. Similarly, Ren also adopted ineffective writing strategies used in low frequency. However, since both of them obtained substantial exposures to L1, and they did not have any problem with their L1 writing.

The last discovery showed that less-skilled writers did minimal revisions as they paid more attention to surface changes than skilled writers. Less-skilled writers were not aware of the significance of revision, which can help them develop and generate their thoughts and they fixed their writing on dealing with common errors such as vocabulary and grammatical mistakes (Alamargot et al., 2011; Lei, 2016). Aside from some similarities, the findings also highlighted quantitative differences. Dinna and Aldy wrote a more extended text in L1 with 598 and 454 words, respectively. Furthermore, they both spent 45 and 40 minutes in the writing stage. However, in writing in L2, Aldy took 6 minutes with more strategies to plan the essay while Dinna spent almost 5 minutes. Observation showed that skilled writers used effective writing strategies because they had ideas of when to pick out and apply the appropriate strategies efficiently. For example, they both knew the right strategies needed to generate ideas, and when to carry out revisions and editing. They read/reread the sentence(s) and paragraph(s) due to several reasons. Skilled writers were aware that writing was not linear and infrequently wrote repetitive sentences. However, the less-skilled writers did not experience writing as repeated processes due to their inability to produce ideas and revise the writings to develop their envisioned meanings.

Regarding less skilled writers, Rita devoted little time when planning for L1 and L2 (less than 2 minutes). Rita only wrote a few keywords before writing, while Ren carried out mental planning. In writing/ translating stage, Rita's writing was linear due to her inability to read/reread, edit and makes revisions. She kept writing without any disruptions. As monitored, Ren applied more writing strategies than Rita. They applied the strategies in low frequency. In the reviewing stage, they only made little changes on the superficial level, such as fixing grammar mistakes, spellings errors, punctuations, and vocabularies.

Therefore, from the findings above, planning and revising strategies were applied more effectively by skilled-writers compared to less-skilled writers. Research conducted by (Lei, 2016) stated that the use of writing strategies by skilled and less skilled student writers from a sociocultural perspective and shows that the two groups differ significantly in internalization of resources although they tend to use similar types of resources. The differences are mainly in the three sub-processes of internalization: noticing, imitating and goal setting. Research conducted by (Alamargot et al., 2011) stated that high WM capacity writers used a different strategy to explore the visual source, making longer writing pauses and producing more detailed procedures, and achieved the communicative goal more efficiently, by introducing more reader supports. In conclusion, we discuss the feasibility of audience awareness training.

\section{Transferability}

Some previous studies proved that similarities in L1and L2 writing strategies indicated that writers transferred their L1 writing strategies to L2 (Berman, 1994; Guo \& Huang, 2018). Furthermore, based on the retrospective interview, each student writer stated that they used 
similar strategies to write in L1 and L2. However, (Karim \& Nassaji, 2013) stated that the transferability of L1 writing strategies is not always positive transfer with negative transfer found in Less-skilled writers. Rita and Ren failed to employ effective writing strategies when they wrote in L1. This is because Rita used a linear writing style and infrequently rehearsed, read/ reread the previous sentence(s) or paragraph to generate ideas, or paused to revise and edit the text. Ren also used the writing strategies in low frequency while writing in L1 and L2. However, both of them were considerably exposed to L1 because they were used to writing daily, which enabled them to produce an acceptable piece of writing. However, when they employed their ineffective L1 writing strategies in their L2, it failed to work as Indonesian's nature is different from that of English. The transfer of their L1writing strategies to $L 2$ enabled them to continuously use ineffective strategies to approach $\mathrm{L} 2$ writing tasks even though these methods are may work in their L1 writing.

The rhetorical habits in an L1 affect the schemata of L2 writing, and that the L1 rhetorical patterns can be transferred to L2 discourse production (Sheldon, 2011; Zhang, 2016). Research conducted by (Wei et al., 2020) stated that: 1) L2 writers' perception of L2 writing difficulty and L2 writing proficiency were found as individual factors relevant to L1-to-L2 rhetorical transfer; 2) L2 writers' perception of L2 writing difficulty was positively associated with the transfer related to the argument organization respecting within-paragraph organization and consideration of a thesis; 3) L2 writers' L2 writing proficiency had a negative association with the transfer that did not reflect the active role of L1 rhetoric. The other research conducted by (Lan et al., 2019) stated that grammatical complexity is regarded as a crucial feature of L2 writing, the construct has been widely utilized in empirical research to gauge L2 writing quality and development, particularly in English.

\section{Conclusion}

Results of the current research showed that all student writers applied similar individual strategies. However, skilled writers employed effective strategies in L1 and L2 from the beginning of their writing process. Furthermore, semi-structured and retrospective interviews showed that they also transferred their effective L1 writing strategies to L2. For instance, skilled writers understood that writing was an ongoing cycle and not a one-step process. Teachers can prepare some writing activities, show them the right strategies in writing. This activity aims to increase students' and teachers' ideas on the right writing strategies. This activity also enables students to monitor their strategic behavior when carrying out the writing assignment and help them discover their effective writing strategies.

\section{References}

Al-Gharabally, M. (2015). the Writing Difficulties Faced By L2 Learners and How To Minimize Them. International Journal of English Language and Linguistics Research, 3(5), 42-49.

Alamargot, D., Caporossi, G., Chesnet, D., \& Ros, C. (2011). What makes a skilled writer? Working memory and audience awareness during text composition. Learning and Individual Differences, 21(5), 505-516. https://doi.org/10.1016/j.lindif.2011.06.001

Alfaki, I. M. (2015). University students' English writing problems. International Journal of English Language Teaching. Published by European Centre for Research Training and Development UK (Www.Eajournals.Org), 3(3), 40-52.

Ardila, I. (2020). Writing Strategies Used by Indonesian EFL Undergraduate Students across Their Proficiency and Gender. JLIC (Journal Of Language Intelrgence And Culture, 1(2), 138-149.

Berman, R. (1994). Learners' Transfer of Writing Skills Between Languages. TESL Canada Journal, 12(1), 29. https://doi.org/10.18806/tesl.v12i1.642 
Bowles, M. A. (2010). The think-aloud controversy in second language research. In The ThinkAloud Controversy in Second Language Research. https://doi.org/10.4324/9780203856338

Chien, S. C. (2012). Students use of writing strategies and their English writing achievements in Taiwan. Asia Pacific Journal of Education, 32(1), 93-112. https://doi.org/10.1080/02188791.2012.655240

Eliwarti, \& Maarof, N. (2014). The Effects of types of writing approaches on EFL students' writing performance. Selt, 11-12(June), 112-119.

Golparvar, S. E., \& Khafi, A. (2021). The role of L2 writing self-efficacy in integrated writing strategy use and performance. Assessing Writing, 47. https://doi.org/10.1016/j.asw.2020.100504

Guo, X., \& Huang, L. S. (2018). Are L1 and L2 strategies transferable? An exploration of the L1 and L2 writing strategies of Chinese graduate students. Language Learning Journal, O(0), 1-23. https://doi.org/10.1080/09571736.2018.1435710

Harmey, S. J. (2020). Co-constructing writing: handing over the reins to young authors. Education 3-13 International Journal of Primary, Elementary and Early Years Education, 1-10. https://doi.org/10.1080/03004279.2020.1732438

Junianti, R., Pratolo, B. W., \& Wulandari, A. T. (2020). The Strategies of Learning Writing Used by EFL Learners at a Higher Education Institution Corresponding Email Article's History. Ethical Lingua, 7(1), 64-73. https://doi.org/10.30605/25409190.131

Khongput, S. (2020). Metastrategies Used by EFL Students in Learning English Writing : LEARN Journal : Language Education and Acquisition Research Network Journal, 13(2), 93-104.

Lan, G., Liu, Q., \& Staples, S. (2019). Grammatical complexity: 'What Does It Mean' and 'So What' for L2 writing classrooms? Journal of Second Language Writing, 46. https://doi.org/10.1016/j.jslw.2019.100673

Latif, M. M. A. (2009). The Problems Identified in the Previous Coding Schemes Used for Analysing L2 / FL Writers 'Think-Aloud Protocols. 1-19.

Lei, X. (2016). Understanding writing strategy use from a sociocultural perspective: The case of skilled and less-skilled writers. System, 60, 105-116. https://doi.org/10.1016/j.system.2016.06.006

Mahmoudi, A. (2017). Effect of Planning on Iranian Intermediate EFL Learners' Mastery of Writing Skill. Theory and Practice in Language Studies, 7(3), 219. https://doi.org/10.17507/tpls.0703.08

Miftah, M. Z. (2015). Through Writing Process Approach. Journal of English as a Foreign Language, 5(1), 9-24. https://doi.org/10.23971/jefl.v5i1.88

Milicevic, A., Woolfe, S., Blazely, A., Lenroot, R., \& Sewell, S. (2020). Enhancing creativity through seven stages of transformation in a graduate level writing course-A mixed method study. Thinking Skills and Creativity, 38. https://doi.org/10.1016/j.tsc.2020.100712

Mistar, J., \& Parlindungan, F. (2014). Strategies of learning English writing skill by Indonesian senior hgh school students. Arab World English Journal, 5(1), 290-303.

Mostafa, T., \& Crossley, S. A. (2020). Verb argument construction complexity indices and L2 writing quality: Effects of writing tasks and prompts. Journal of Second Language Writing, 49. https://doi.org/10.1016/j.jslw.2020.100730 
Ortega, L. (2015). Syntactic complexity in L2 writing: Progress and expansion. Journal of Second Language Writing, 29, 82-94. https://doi.org/10.1016/j.jslw.2015.06.008

Sheldon, E. (2011). Rhetorical differences in RA introductions written by English L1 and L2 and Castilian Spanish L1 writers. Journal of English for Academic Purposes, 10(4), 238-251. https://doi.org/10.1016/j.jeap.2011.08.004

Sumarwati, S. (2019). Peningkatan Kualitas Pembelajaran Menulis Melalui Penerapan Pendekatan Proses Di Kelas V Sekolah Dasar. Logat, 6(2), 151-167. https://doi.org/10.36706/logat.v6i2.206

Victori, M. (1999). An analysis of writing knowledge in EFL composing: A case study of two effective and two less effective writers. System, 27(4), 537-555. https://doi.org/10.1016/S0346-251X(99)00049-4

Wei, X. (2020). Assessing the metacognitive awareness relevant to L1-to-L2 rhetorical transfer in L2 writing: The cases of Chinese EFL writers across proficiency levels. Assessing Writing, 44. https://doi.org/10.1016/j.asw.2020.100452

Wei, X., Zhang, L. J., \& Zhang, W. (2020). Associations of L1-to-L2 rhetorical transfer with L2 writers' perception of L2 writing difficulty and L2 writing proficiency. Journal of English for Academic Purposes, 47. https://doi.org/10.1016/j.jeap.2020.100907

Wong, K. S. R., \& Russak, S. (2020). Hong Kong Cantonese L1 preschool children's name writing in English L2. Cognitive Development, 56. https://doi.org/10.1016/j.cogdev.2020.100957

Zhang, L. J. (2016). Reflections on the pedagogical imports of western practices for professionalizing ESL/EFL writing and writing-teacher education. Australian Review of Applied Linguistics, 39(3), 203-232. https://doi.org/10.1075/aral.39.3.01zha 